\title{
May Medium Cut-Off Dialysis Membranes Have Impact on Outcome of COVID-19 Hemodialysis Patients?
}

\section{SERKAN FEYYAZ YALIN ( $\sim$ serkanfyalin@yahoo.com)}

Kartal Dr. Lütfı Kırdar Training and Research Hospital, Istanbul

\section{AHMET MURT}

Istanbul University-Cerrahpasa, Cerrahpasa Faculty of Medicine

\section{MEVLUT TAMER DINCER}

Istanbul University-Cerrahpasa, Cerrahpasa Faculty of Medicine

\section{ERGUN PARMAKSIZ}

Kartal Dr. Lütfı Kırdar Training and Research Hospital, Istanbul

\section{SERAP YADIGAR}

Kartal Dr. Lütfı Kırdar Training and Research Hospital, Istanbul

\section{MEHMET RIZA ALTIPARMAK}

Istanbul University-Cerrahpasa, Cerrahpasa Faculty of Medicine

\section{Research Article}

Keywords: COVID-19, hemodialysis, hemodialysis membranes, outcome

Posted Date: September 9th, 2020

DOl: https://doi.org/10.21203/rs.3.rs-72077/v1

License: (c) (1) This work is licensed under a Creative Commons Attribution 4.0 International License. Read Full License 


\section{Abstract}

Purpose: Severe acute respiratory syndrome coronavirus 2 which is a novel type of coronavirus, may lead to high levels of expression of inflammatory cytokines. Medium cut-off membranes may make greater clearances for large-middle molecules (including cytokines) than low flux membranes. In this study, we aimed to evaluate impact of type of hemodialysis membranes on outcome of COVID 19+ hemodialysis patients.

Methods: Forty nine COVID 19 + hemodialysis patients were included into study. The patients were categorized into two groups regarding type of hemodialysis membranes. Clinical data, etiologies of kidney diseases, comorbidities, laboratory and radiologic findings, antiviral, anti-cytokine treatments, and hemodialysis data were taken from medical records.

Results: Medium cut-off membranes were used in 15 patients and low flux membranes were used in 34 patients. There were significantly more patients with comorbidities in medium cut-off group compare to low flux group $(p=0,014)$. CRP and ferritin which are each surragates of cytokine storm in COVID-19, were significantly higher in medium cut-off membrane group compare to low flux group $(p=0,00,0,01$, respectively).

Conclusion: It may be an option to use medium cut-off membranes in hemodialysis patients with COVID 19 in order to reduce cytokine levels and prevent cytokine storm.

\section{Introduction}

Severe acute respiratory syndrome coronavirus 2 (SARS-CoV-2) which is a novel type of coronavirus, first emerged at December 2019 in Wuhan, China [1]. It has been reported that SARS-CoV may damage the respiratory system and causes serious outbreaks with high mortality rate $[2,3]$. The most common manifestation of infection is pneumonia which is characterized by bilateral infiltrates in the lung $[4,5,6]$. Positive reverse transcription-polymerase chain reaction (RT-PCR) assay for COVID-19 from upper respiratory system confirm the diagnosis[7]. Reports indicate that individuals with older age and/or with underlying illnesses, such as diabetes mellitus, hypertension, or cardiovascular diseases, indicate poor prognosis for COVID-19 [4,8,9]. These comorbidities are common in hemodialysis (HD) patients. Moreover, patients with chronic kidney failure have impaired immune function involving both innate and adaptive systems. These result in both immunodepression which increases vulnerability to infections [10].

During the course of COVID-19, high levels of expression of inflammatory cytokines (interleukin 1 beta (IL-1 $\beta$ ), interferon gamma (IFN- $\gamma$ ), interferon gamma-induced protein 10 (IP-10), and monocyte chemoattractant protein 1 (MCP-1) ) may activate the T-helper type 1 (Th1) cell response [11]. Th1 activation is paramount importance of activation of specific immunity [12]. Severity of the disease is well correlated with high serum levels of interleukin-2 receptor (IL-2R) and interleukin 6 (IL-6) [13]. IL-6 stimulates production of CRP [14]. In addition, the activation of the monocyte-macrophage system, 
which is a vital part of inflammatory storm, stimulates ferritin production [15]. The cytokine storm causes organ dysfunction, which may cause death [16].

$\mathrm{HD}$ is an extracorporeal process in which waste products that accumulate in patients with end-stage renal disease, is removed by a semipermeable membrane [17]. Three type of hemodialysis membranes are described: low flux (LF), high flux (HF) and medium cut-off (MCO) [18]. MCO membranes may make greater clearances and intradialytic reduction ratios for large-middle molecules (including cytokines) than LF and HF membranes [19].

In this study, we aimed to evaluate impact of type of hemodialysis membranes (MCO membrane versus LF membrane) on outcome of COVID 19+ HD patients.

\section{Methods}

\section{Patients and methods}

\section{Study setting}

This study was performed in two tertiary care university hospitals which are serving in an area with approximately 16 million residents. The study was done in compliance to the Declaration of Helsinki. Institutional approval was taken from the local ethical review committee. The participants' identities were kept confidential.

\section{Study population}

All HD files of the COVID $19+$ patients who had chronic HD treatment between the time period of 11 March 2020 and 15 May 2020 were examined. Hospital records were evaluated retrospectively. Forty nine COVID $19+$ HD patients were included into study.

The patients were categorized into two groups regarding type of hemodialysis membranes: Group 1 patients underwent HD with MCO membranes and group 2 with LF membranes.

\section{Data collection}

The medical data of the patients were retrospectively obtained using standardized forms by a physician who did not know the outcome of the patients. Clinical data, etiologies of kidney diseases, comorbidities, laboratory and radiologic findings, antiviral, anti-cytokine treatments, and HD data were taken from medical records.

\section{Patient management}

The positive RT-PCR and/or radiological findings were used to confirm the diagnosis. Disease activity was described as follows: asymptomatic, mild disease (symptoms with or without mild dyspnea), 
moderate disease (dyspnea requiring oxygen therapy) and severe disease (dyspnea requiring intensive care treatment). All HD patients were hospitalized due to high mortality risk for COVID 19.

\section{Antiviral and cytokine-targeted therapy}

Our managements were based on a national guide written by the scientific board of our country and published by our health ministry. All of the hospitalized patients were initially medicated with hydroxychloroquine (400 mg BID for the first day, and then $200 \mathrm{mg}$ BID for four days; oral) and azithromycin (500 mg QD for the first day, and then $250 \mathrm{mg}$ QD for the four days; oral) and oseltamivir (75 mg BID for 5 days). Favipiravir (1600 mg BID for the first day, and then $600 \mathrm{mg}$ BID for the four days; oral) was given to refractory cases. Tocilizumab (400 mg QD for two days; intravenous) was used in the management of cytokine release syndrome which especially developed in severe cases.

\section{Anticoagulation and oxygen treatment}

Standart heparin or low molecular weight heparin was used in hemodialysis sessions unless contraindicated. Half dose low molecular weight heparin was used in all patients at hemodialysis free days unless contraindicated. Oxygen treatment was givento the patients with oxygen saturation below $92 \%$. If respiratory failure progressed, firstly non-invasive ventilation and then mechanical ventilation was performed in the intensive care unit .

\section{Statistical analysis}

Data were expressed as mean \pm SD. Data of HD patients with LF membrane and MCO membrane were compared using Student's $t$ test and chi-square test. All computations were made using the SPSS for Windows v. 17.0 software (SPSS Inc., Chicago, IL, USA). $P$ values of $<.05$ were considered significant.

\section{Results}

Forty-nine HD patients were enrolled into the study. Etiologies of kidney disease in group 1 were as follows: hypertension in $5(35,7 \%)$ patients, diabetes mellitus in $3(21,5 \%)$, collagen vascular diseases in 1 (7,1\%), chronic glomerulonephritis in $1(7,1 \%)$, autosomal dominant polycystic kidney disease (ADPKD) in $1(7,1 \%)$ and unknown disease in $3(21,5 \%)$. Etiologies of kidney disease in group 2 were as follows: diabetes mellitus in $12(34,3 \%)$ patients, hypertension in $9(25,7 \%)$, collagen vascular diseases in $3(8,6 \%)$, chronic glomerulonephritis in $1(2,8 \%)$, ADPKD in $1(2,8 \%)$ and unknown in $9(25,7 \%)$.

MCO (Theranova 400, Baxter ${ }^{\text {TM }}$, U.S.A) membranes were used in 15 patients and LF membranes (Elisio$21 \mathrm{M}$, Nipro ${ }^{\mathrm{TM}}$, Japan) were used in 34 patients. Initial demographics and clinical characteristics and labarotory findings of two groups are shown in Table 1. Mean age of two groups was similar. There were significantly more patients with comorbidities in MCO group compare to LF group $(p=0,014)$. Kt/ , serum creatinine and sodium levels and platelet count were significantly higher in MCO group compare to LF group ( $p=0,047,0,001,0,002,0,005$, respectively). CRP and ferritin which are each surragates of cytokine 
storm in COVID-19, were significantly higher in MCO group compare to LF group $(p=0,00,0,01$, respectively).

Symptoms and physical findings during onset of diagnosis are shown in Table 2. Majority of the patients had fever, cough, dyspnea and myalgia. All of the patients had radiological findings for Covid- 19 . Whereas, 21(42,8\%) patients had positive PCR test for COVID-19.

Disease activity of the patients during onset of diagnosis is shown in Table 3. Regarding LF group, majority of the patients had mild- moderate disease activity. Whereas, there were more severe patients in MCO group compare to LF group in terms of disease activity.

Regarding treatment types, two groups were treated by similar drugs according to severity of the disease (Table 4). In the MCO group, more patients needed to require favipravir and tocilizumab treatments compare to LF group.

The outcomes of two groups are shown in Table 5. Length of hospital stay was significantly longer in MCO group compare to LF group $(p=0,012)$. However, there were no significant differences between two groups in terms of need for intensive care unit and death.

\section{Discussion}

COVID-19 is a life-threatening disease, has affected all countries recently. One of the most important complication of virus is hemophagocytic lymphohistiocytosis (HLH)- macrophage activation syndrome (MAS) via cytokine storm. Laboratory signs and symptoms of HLH-MAS include severe elevation in acute phase parameters such as CRP and ferritin, persistent fever, hepatosplenomegaly, cytopenias, hypertriglyceridemia, hypofibrinogenemia and elevation of AST [20]. HLH-MAS causes organ dysfunction, which may cause death [16].

There is no currently cure for COVID-19. Therefore, clinicians are nowadays trying treat COVID-19 patients who progressed to HLH-MAS by some agents such as anti-viral agents, glucocorticoids, IL-6 antagonists, IL-1 antagonists, intravenous immunoglobulin, convalescent plasma, janus kinase inhibitors [20]. Also it was speculated that blood purification technology can prevent COVID-19 patients from severe pneumonia via cytokine clearance $[21,22]$.

MCO is a novel type membrane for HD. In a study performed by Kim et al., it was showed that HD with MCO membranes achieved significantly greater reduction ratio of large middle molecules (including cytokines such as IL-1 and IL-6), than HD with conventional membranes and online-hemodiofiltration [19].

In this study, we divided HD patients into two groups (LF membrane versus MCO membrane) in order to evaluate impact of MCO membranes on survival of patients with COVID-19.

Regarding clinical symptoms and laboratory results (especially CRP and ferritin levels), there were more severe COVID-19 patients in MCO group compare to LF group. In addition, MCO group patients stayed 
longer in the hospital due to possibly severity of disease. Despite these data, there were no differences between two groups in terms of need for intensive care unit and death. In the light of these results, we can assume that MCO membranes may protect patients from HLH-MAS via cytokine purification.

The limitations of our study are that we performed this study in a small population. In small groups, it may be difficult to interpret statististical analysis. In addition, we could not measure IL-6 levels before and after HD sessions in order to see reduction in IL-6 level which is a good marker for inflammation in COVID-19 disease.

In conclusion, it may be an option to use MCO membranes in HD patients with COVID 19 in order to reduce cytokine levels and prevent cytokine storm. Also we can speculate that COVID-19 patients with cytokine storm may benefit from standart HD with MCO membranes regardless renal failure.

\section{Declarations}

Funding: There is no funding

Conflicts of interest/Competing interests: There is no conflict of interest

Ethics approval: Ethics approval was obtained from local committee

Consent to participate: Consent of participation was obtained

Consent for publication: Consent for publication was obtained

Availability of data and material: Not applicable

Code availability: Not applicable

Authors' contributions:

Design, concept, data analysis, wrote paper: S.F.Y

Design, concept, data analysis, wrote paper : M.R.A

Data collection, data analysis, concept : A.M, M.T.D, E.P, S.Y

\section{References}

1- Yang C-L, Qiu X, Zeng Y-K, et al (2020) Coronavirus disease 2019: a clinical review. Eur Rev Med Pharmacol Sci 24:4585-96. doi:10.26355/eurrev_202004_21045.

2- Chen N, Zhou M, Dong X, et al (2020) Epidemiological and clinical characteristics of 99 cases of 2019 novel coronavirus pneumonia in Wuhan, China: a descriptive study. Lancet 395:507-513. doi:10.1016/S0140-6736(20)30211-7. 
3- Pisani A, Rizzo M, Angelucci V, et al (2020) COVID-19 Experience in Hemodialysis Patients: A Cue for Therapeutic Heparin-Based Strategies? Nephron 1-3. doi:10.1159/000508638.

4- Yang $X, Y u Y, X u$ J, et al (2020) Clinical course and outcomes of critically ill patients with SARS-CoV-2 pneumonia in Wuhan, China: A single-centered, retrospective, observational study. Lancet Respir Med 8:475-481. doi:10.1016/S2213-2600(20)30079-5.

5 - Kooraki S, Hosseiny M, Myers L, et al (2020) Coronavirus (COVID-19) Outbreak: What the Department of Radiology Should Know. J Am Coll Radiol 17:447-51. doi:10.1016/j.jacr.2020.02.008.

6- Lomoro P, Verde F, Zerboni F, et al (2020) COVID-19 pneumonia manifestations at the admission on chest ultrasound, radiographs, and CT: single-center study and comprehensive radiologic literature review. Eur J Radiol Open 7:100231. doi:10.1016/j.ejro.2020.100231.

7- Patel A, Jernigan DB; 2019-nCoV CDC Response Team (2020) Initial Public Health Response and Interim Clinical Guidance for the 2019 Novel Coronavirus Outbreak - United States, December 31, 2019February 4, 2020. MMWR Morb Mortal Wkly Rep 69:140-146. doi:10.15585/mmwr.mm6905e1.

8- $\quad$ Xiong F, Tang H, Liu L, et al (2020) Clinical Characteristics of and Medical Interventions for COVID19 in Hemodialysis Patients in Wuhan, China. J Am Soc Nephrol 31:1387-1397. doi:10.1681/ASN.2020030354.

9- R. Channappanavar, S. Perlman (2017) Pathogenic human coronavirus infections: causes and consequences of cytokine storm and immunopathology. Semin Immunopathol 39:529-539. doi:10.1007/s00281-017-0629-x.

10- Kato S, Chmielewski M, Honda $\mathrm{H}$, et al (2008)Aspects of immune dysfunction in end-stage renal disease. Clin J Am Soc Nephrol 3:1526-1533. doi:10.2215/CJN.00950208.

11- Huang C, Wang Y, Li X, et al (2020) Clinical features of patients infected with 2019 novel coronavirus in Wuhan, China. Lancet 395:497-506. doi:10.1016/S0140-6736(20)30183-5.

12- Marchingo JM, Sinclair LV, Howden AJM, et al (2020) Quantitative analysis of how Myc controls T cell proteomes and metabolic pathways during T cell activation. Elife. 9:e53725. doi:10.7554/eLife.53725.

13- Chen L, Liu H-G, Liu W, et al (2020) Analysis of clinical features of 29 patients with 2019 novel coronavirus pneumonia. Honghua Jie He He Hu Xi Za Zhi 43:E005. doi:10.3760/cma.j.issn.10010939.2020.03.013.

14- Del Giudice M, Gangestad SW (2018) Rethinking IL-6 and CRP: Why they are more than inflammatory biomarkers, and why it matters. Brain Behav Immun 70:61-75. doi:10.1016/j.bbi.2018.02.013. 
15- Guo W, Li M, Dong Y, et al (2020) Diabetes is a risk factor for the progression and prognosis of COVID19. Diabetes Metab Res Rev e3319. doi:10.1002/dmrr.3319.

16- Peipei Song, Wei Li, Jianqin Xie, et al (2020) Cytokine storm induced by SARS-CoV-2. Clin Chim Acta 509: 280-287. doi:10.1016/j.cca.2020.06.017.

17- Ronco, C., Clark, W.R (2018) Haemodialysis membranes. Nat Rev Nephrol 1:394-410.

doi:10.1038/s41581-018-0002-x.

18- Zweigart C, Boschetti-de-Fierro A, Hulko M, et al (2017) Medium cut-off membranes - closer to the natural kidney removal function. Int J Artif Organs 40:328-334. doi:10.5301/ijao.5000603.

19- Kim, T.H., Kim, S., Kim, et al (2019) Removal of large middle molecules via haemodialysis with medium cut-off membranes at lower blood flow rates: an observational prospective study. BMC Nephrol 21:2. doi:10.1186/s12882-019-1669-3.

20- B. Halacli, A.Topeli (2020) Treatment of the Cytokine Storm in COVID-19. J Crit Intensive Care 1:36-40. https://doi.org/10.37678/dcybd.2020.2434.

21- Ke C, Wang Y, Zeng X, et al (2020) 2019 Novel coronavirus disease (COVID-19) in hemodialysis patients: A report of two cases. Clin Biochem 81:9-12. doi:10.1016/j.clinbiochem.2020.04.008.

22- Ronco C, Bagshaw SM, Bellomo R, et al (2020) Extracorporeal Blood Purification and Organ Support in the Critically III Patient during COVID-19 Pandemic: Expert Review and Recommendation. Blood Purif 111. doi:10.1159/000508125.

\section{Tables}

Table 1. Demographics and clinical characteristics and laboratory findings of two groups. 


\begin{tabular}{|c|c|c|c|}
\hline & $\begin{array}{l}\text { Medium cut-off membrane } \\
\qquad(\mathrm{n}=15)\end{array}$ & $\begin{array}{l}\text { Low flux membrane } \\
\qquad(\mathrm{n}=34)\end{array}$ & $\mathbf{P}$ \\
\hline Age (year) & 65,5 & 62.7 & 0,519 \\
\hline Gender (male/female) & $7 / 8$ & $15 / 19$ & 0,869 \\
\hline Dialysis length (month) & $39,5 \pm 40,7$ & $50,2 \pm 45,1$ & 0,442 \\
\hline Number of dialysis session per week (3 / 2) & $12 / 3$ & $30 / 4$ & \\
\hline $\mathrm{Kt} / \mathrm{V}$ & $1,36 \pm 0,24$ & $1,24 \pm 0,14$ & 0,047 \\
\hline Presence of hypertension (\%) & $12(80,0)$ & $27(79,4)$ & 0,967 \\
\hline Presence of diabetes mellitus (\%) & $5(33,3)$ & $14(41,1)$ & 0,604 \\
\hline Presence of comorbidities † (\%) & $13(86,6)$ & $10(29,4)$ & 0,014 \\
\hline Use of ACE-İ / ARB ${ }^{\ddagger}(\%)$ & $3(20,0)$ & $2(5,8)$ & 0,132 \\
\hline Use of immunosuppresive drugs & 0 & 0 & \\
\hline Hypotension during onset of diagnosis (\%) & $2(13,3)$ & $2(5,8)$ & 0,380 \\
\hline Hemoglobin $(\mathrm{g} / \mathrm{dl})$ & $9,8 \pm 1,4$ & $10,3 \pm 1,6$ & 0,40 \\
\hline White blood cells $\left(10^{3} / \mathrm{uL}\right)$ & $9,086 \pm 4,701$ & $7,947 \pm 3,936$ & 0,383 \\
\hline Lymphocyte $\left(10^{3} / \mathrm{uL}\right)$ & $1053 \pm 0,422$ & $1085 \pm 0,602$ & 0,853 \\
\hline Platelet count $\left(10^{3} / \mathrm{uL}\right)$ & $265506 \pm 76691$ & $196058 \pm 64825$ & 0,002 \\
\hline CRP (mg/L) & $182,7 \pm 83,6$ & $94,4 \pm 69,5$ & 0,000 \\
\hline Procalcitonin (ng/ml) & $1,1 \pm 0,77$ & $6,8 \pm 12,8$ & 0,124 \\
\hline Ferritin $(\mu \mathrm{g} / \mathrm{L})$ & $5505 \pm 11072$ & $608,6 \pm 338,3$ & 0,015 \\
\hline Serum creatinine (mg/dl) & $8,7 \pm 2,9$ & $6,07 \pm 2,07$ & 0,001 \\
\hline Sodium (mmol/L) & $137 \pm 4,1$ & $134,1 \pm 2,6$ & 0,005 \\
\hline Potassium (mmol/L) & $4,8 \pm 0,91$ & $4,8 \pm 0,82$ & 0,976 \\
\hline Calcium (mg/dl) & $8,1 \pm 0,89$ & $8,2 \pm 1,1$ & 0,956 \\
\hline Serum albumin $(\mathrm{g} / \mathrm{L})$ & $3,1 \pm 0,59$ & $3,7 \pm 0,35$ & 0,001 \\
\hline Presence of lesion on chest tomography (\%) & $15(100)$ & $34(100)$ & \\
\hline
\end{tabular}

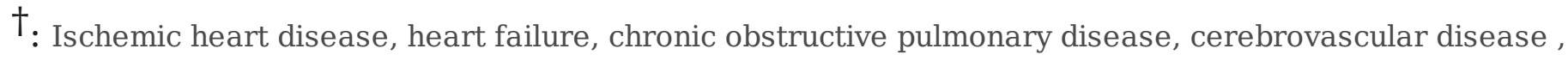
malignancy, chronic liver disease, systemic vasculitis ${ }_{\text {: }}$ ACE-İ; Angiotensin-converting enzyme inhibitors. ARB: Angiotensin II receptor blockers

Table 2. Symptoms and physical findings during onset of diagnosis. 


\begin{tabular}{|l|l|l|}
\hline & \multicolumn{1}{|c|}{$\begin{array}{c}\text { Medium cut-off membrane } \\
(\mathbf{n = 1 5 )}\end{array}$} & $\begin{array}{c}\text { Low flux membrane } \\
(\mathbf{n}=34)\end{array}$ \\
\hline Fever (\%) & $8(53,3 \%)$ & $23(67,6 \%)$ \\
\hline Cough (\%) & $7(46,6 \%)$ & $16(47 \%)$ \\
\hline Dyspnea (\%) & $10(66,6 \%)$ & $15(44,1 \%)$ \\
\hline Fatigue (\%) & $11(73,3 \%)$ & $25(73,5 \%)$ \\
\hline Myalgia (\%) & $10(66,6 \%)$ & $19(55,8 \%)$ \\
\hline Diarrhea (\%) & $1(6,6 \%)$ & $1(2,9 \%)$ \\
\hline Other (\%) & $1(6,6 \%)$ & $3(8,8 \%)$ \\
\hline Mean respiratory rate (min) & $22,8 \pm 4,2$ & $22,6 \pm 5,1$ \\
\hline Mean heart rate (min) & $81,11 \pm 11,6$ & $77,3 \pm 22$ \\
\hline Mean blood pressure (mm/Hg) & $129,1 \pm 21,1 / 75,7 \pm 10,3$ & $126,1 \pm 17,5 / 80 \pm 9,8$ \\
\hline
\end{tabular}

Table 3. Disease activity of the patients during onset of diagnosis.

\begin{tabular}{l|l|l|}
\hline & \multicolumn{1}{|c|}{$\begin{array}{c}\text { Medium cut- } \\
\text { off membrane } \\
(\mathrm{n}=15)\end{array}$} & \multicolumn{1}{|c|}{$\begin{array}{c}\text { Low flux } \\
\text { membrane } \\
(\mathrm{n}=34)\end{array}$} \\
\hline $\begin{array}{l}\text { symptomatic } \\
\text { Jiagnosis with screening) }\end{array}$ & 0 & $1(2,9 \%)$ \\
\hline $\begin{array}{l}\text { lild disease } \\
\text { ymptoms with or without mild dyspnea) }\end{array}$ & $1(6,7 \%)$ & $17(50 \%)$ \\
\hline $\begin{array}{l}\text { loderate } \\
\text { lyspnea requiring oxygen therapy) }\end{array}$ & $4(26,6 \%)$ & $16(47,1 \%)$ \\
$\begin{array}{l}\text { evere disease } \\
\text { lyspnea requiring intensive care } \\
\text { eatment) }\end{array}$ & $10(66,7 \%)$ & 0 \\
\hline
\end{tabular}

Table 4. Types of treatments against COVID 19. 


\begin{tabular}{l|l|l|}
\hline & $\begin{array}{c}\text { Medium cut-off membrane } \\
(\mathbf{n}=\mathbf{1 5})\end{array}$ & $\begin{array}{c}\text { Low flux membrane } \\
(\mathbf{n}=34)\end{array}$ \\
\hline $\begin{array}{l}\text { (Hydroxychloroquine + Oseltamivir } \\
\text { Azithromycin) }\end{array}$ & $15(100 \%)$ & $34(100 \%)$ \\
\hline + Favipiravir & $7(46,6 \%)$ & $6 \quad(17,6 \%)$ \\
\hline + Favipiravir + Tocilizumab & $2(13,3 \%)$ & $1 \quad(2,9 \%)$ \\
\hline
\end{tabular}

Table 5. Outcomes of two groups.

\begin{tabular}{|l|c|c|c|}
\hline & $\begin{array}{l}\text { Medium cut- } \\
\text { off membrane } \\
(\mathbf{n}=15)\end{array}$ & $\begin{array}{l}\text { Low flux } \\
\text { membrane } \\
(\mathbf{n}=34)\end{array}$ & $\mathrm{P}$ \\
\hline Length of hospital stay (day) & $20,9 \pm 19,8$ & $10,8 \pm 7,4$ & $\mathbf{0 , 0 1 2}$ \\
\hline $\begin{array}{l}\text { Need for intensive care unit } \\
\text { (\%) }\end{array}$ & $6(40.0)$ & $12(35.2)$ & 0,753 \\
\hline Death (\%) & $4(26.6)$ & $9(26.4)$ & 0,989 \\
\hline
\end{tabular}

